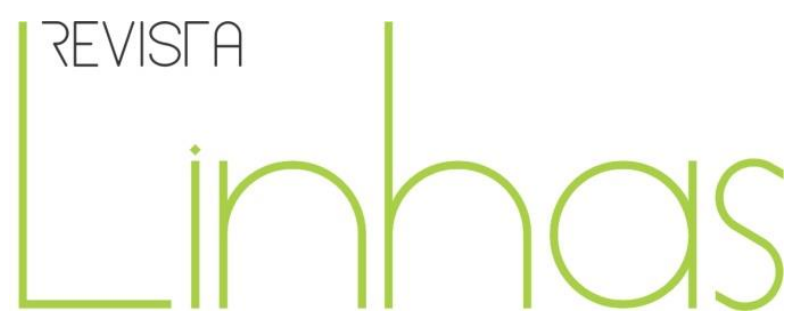

\title{
Organização e oferta do Atendimento Educacional Especializado para alunos com deficiência intelectual e múltipla na Baixada Fluminense
}

\begin{abstract}
Resumo
Em 2008, com a implementação da Política Nacional de Educação Especial na Perspectiva da Educação Inclusiva, inúmeras ações têm sido realizadas no âmbito nacional e, também, localmente nas redes de ensino para garantir os direitos educacionais e sociais de pessoas com deficiência. Como essas políticas têm impactado nas necessárias transformações das práticas pedagógicas destinadas às pessoas com deficiência? Que suportes e apoios pedagógicos têm sido oferecidos para garantir a escolarização desses sujeitos? A partir de tais questões, apresentamos os dados de duas pesquisas qualitativas realizadas em sete redes de ensino da Baixada Fluminense sobre a escolarização de pessoas com deficiência intelectual e múltipla, focalizando os caminhos encontrados pelas redes de ensino na organização e na oferta do Atendimento Educacional Especializado. Como procedimentos de coleta de dados, realizamos entrevistas semiestruturadas com os gestores responsáveis pela Educação Especial e analisamos as respectivas diretrizes educacionais municipais entre 2013 e 2015. Os resultados mostram, entre outros aspectos, um aumento nas matrículas desses sujeitos em turmas comuns de ensino; uma variedade de suportes organizados e implementados a partir das estruturas educativas locais, assim como as perspectivas colocadas pelos Planos Municipais de Educação e as contradições e os desafios enfrentados na escolarização de alunos com deficiência intelectual e, sobretudo, com deficiência múltipla.
\end{abstract}

Palavras-chave: Educação Inclusiva; Atendimento Educacional Especializado; Deficiência Intelectual; Deficiência Múltipla.

\section{Márcia Denise Pletsch}

Universidade Federal Rural do

Rio de Janeiro - UFRRJ -

$$
\mathrm{RJ} / \text { Brasil }
$$

marciadenisepletsch@gmail.com

Maíra Gomes de Souza da Rocha

Secretaria Municipal de Educação

de Duque de Caxias - RJ/Brasil

mairagsrocha@gmail.com

\section{Mariana Corrêa Pitanga de Oliveira}

Universidade Federal Rural do Rio de Janeiro - UFRRJ $\mathrm{RJ} /$ Brasil

pitanga.mariana@yahoo.com.br

\footnotetext{
Para citar este artigo:

PLETSCH, Márcia Denise; ROCHA, Maíra Gomes de Souza da; OLIVEIRA, Mariana Corrêa Pitanga de. Organização e oferta do Atendimento Educacional Especializado para alunos com deficiência intelectual e múltipla na Baixada Fluminense. Revista Linhas. Florianópolis, v. 17, n. 35, p. 102-121, set./dez. 2016.
}

DOI: $10.5965 / 1984723817352016102$

http://dx.doi.org/10.5965/1984723817352016102 


\title{
Organization and provision of the Specialized Education Service for students with intellectual and multiple disabilities in Baixada Fluminense
}

\begin{abstract}
In 2008, with the implementation of the National Policy on Special Education in the Perspective of Inclusive Education, numerous actions have been undertaken at the national level and also locally in educational networks to ensure the education and social rights of people with disabilities. How have these policies impacted on the necessary transformations of teaching practices directed to people with disabilities? What teaching supports and aids have been provided to ensure the schooling of these individuals? From these questions, we present data from two qualitative researches conducted in seven educational networks in Baixada Fluminense (Rio de Janeiro - Brazil) on schooling of people with intellectual and multiple disabilities, focusing on the ways found by the educational networks in the organization and provision of Specialized Education Service. As data collection procedures, we conducted semi-structured interviews with the managers responsible for Special Education and analyzed the respective municipal educational guidelines between 2013 and 2015. The results show, among other aspects, an enrollment increasement of these individuals in common education classes; a variety of organized and implemented support from the local educational structures, as well as the perspectives raised by the Municipal Education Guidelines and the contradictions and challenges faced in the schooling of students with intellectual disabilities, and, above all, multiple disabilities.
\end{abstract}

Keywords: Inclusive Education; Specialized Educational Service; Intellectual Disability; Multiple Disability. 
Organizar o elo entre o que o aluno realiza e o que a escola oferece como processo de ensino e aprendizagem é uma tarefa dimensionada pelo AEE e pelos professores que, numa atuação colaborativa, poderiam vislumbrar, de forma mais efetiva, processos de ensino para os professores e de aprendizagem para os alunos. A possibilidade de ações educacionais colaborativas entre professores nos leva a crer que as finalidades da educação inclusiva poderiam ser mais palpáveis, já que todos se responsabilizariam pelo processo. $\mathrm{E}$, que as ações no cotidiano escolar poderiam ser capazes de inibir caminhos que viessem a caracterizar o espaço do AEE como segregador, como vimos acontecer com as classes de progressão, classes especiais, classes de apoio e até mesmo com a antiga sala de recursos.

(BRAUN, 2012, p. 47)

O presente artigo resulta das discussões e análises que têm sido realizadas pelo grupo de pesquisa Observatório da Educação Especial e inclusão escolar: práticas curriculares e processos de ensino e aprendizagem ${ }^{1}$, a partir do desenvolvimento de dois projetos de pesquisa, a saber: "A escolarização de alunos com deficiência intelectual: políticas públicas, processos cognitivos e avaliação da aprendizagem (2013-2017)”2 e "Escolarização e desenvolvimento de alunos com deficiência intelectual e múltipla na Baixada Fluminense (2015-2019)"'3.

Considerando que o foco do grupo de pesquisa desde a sua criação, em 2009, tem sido investigar os processos de escolarização e suportes oferecidos para o público-alvo da Educação Especial, em diferentes redes de ensino da Baixada Fluminense, a partir das diretrizes federais, este artigo apresenta resultados sobre os caminhos encontrados pelas redes de ensino na organização e na oferta do Atendimento Educacional Especializado para alunos com deficiência intelectual e múltipla.

A implementação da Política Nacional de Educação Especial na Perspectiva da Educação Inclusiva (BRASIL, 2008) e das Diretrizes Operacionais do Atendimento Educacional Especializado - AEE (BRASIL, 2009) nos colocam questões sobre: Como essas

\footnotetext{
${ }^{1}$ Disponível em: <http://r1.ufrri.br/im/oeeies/>.

${ }^{2}$ Investigação desenvolvida em rede pelos Programas de Pós-Graduação em Educação da UFRRJ, UDESC e UNIVALI, financiado pelo Programa Observatório da Educação (OBEDUC) da Coordenação de Aperfeiçoamento de Pessoal e Nível Superior (CAPES). O projeto contou também, entre os anos de 2012 e 2013, com apoio financeiro da Fundação de Amparo à Pesquisa do Estado do Rio de Janeiro (FAPERJ) por meio do Edital Apoio a projetos de pesquisa na área de humanidades/ 2011.

${ }^{3}$ Projeto financiado pelo Programa Jovem Cientista do Nosso Estado, da Fundação de Amparo à Pesquisa do Estado do Rio de Janeiro (FAPERJ) e pela Chamada Ciências Humanas, Sociais e Sociais Aplicadas (MCTI $n^{\circ}$ 25/2015), do Conselho Nacional de Desenvolvimento Científico e Tecnológico (CNPq).
} 
políticas têm impactado nas necessárias transformações das práticas pedagógicas destinadas às pessoas com deficiência intelectual e múltipla? E que suportes e apoios pedagógicos têm sido oferecidos para garantir a escolarização desses sujeitos?

Partindo dessas questões, nossas pesquisas no contexto da Baixada Fluminense/RJ nos revelam a situação educacional desses alunos e os desafios que ainda persistem na realidade dos municípios investigados: Belford Roxo, Duque de Caxias, Mesquita, Nilópolis, Nova Iguaçu, São João de Meriti e Queimados. Como procedimentos de coleta de dados, além da pesquisa e análise dos documentos como os Planos Municipais de Educação, realizamos entrevistas semiestruturadas com os gestores responsáveis pela Educação Especial dos referidos municípios.

Neste artigo, discutiremos, a partir dos dados coletados e dos indicadores nacionais (BRASIL, 2015), os conceitos e as dimensões que envolvem a escolarização desses sujeitos, assim como se organizam os suportes especializados, focando o AEE. Para tanto, cabe primeiramente explicitar os conceitos de deficiência intelectual e deficiência múltipla adotados em nossas pesquisas. De acordo com o conceito instituído no âmbito da Convenção sobre os Direitos das Pessoas com Deficiência e o Censo Escolar do Instituto Nacional de Estudos e Pesquisas Educacionais Anísio Teixeira (INEP), consideramos estudantes com deficiência "aqueles que têm impedimentos de longo prazo, de natureza física, intelectual ou sensorial, os quais, em interação com diversas barreiras, podem obstruir sua participação plena e efetiva na sociedade em igualdade de condições com as demais pessoas" (BRASIL, 2016, p. 66). Nesse documento, a deficiência intelectual é definida por alterações significativas, tanto no desenvolvimento intelectual como na conduta adaptativa, na forma expressa em habilidades práticas, sociais e conceituais. A deficiência múltipla, por sua vez, é definida pela associação, de dois ou mais tipos de deficiência (intelectual/visual/auditiva/física).

Como podemos observar, no caso da deficiência intelectual, as indicações oficiais seguem o conceito da Associação Americana de Deficiência Intelectual e Desenvolvimento (AMERICAN ASSOCIATION ON INTELLECTUAL AND DEVELOPMENTAL DISABILITIES, 2010). Nossas pesquisas indicam que essa população representa o maior número do público inerente à Educação Especial no país (BRASIL, 2015; 2016). Os microdados do INEP (2014) mostram que esse percentual chega a 69,7\% das matrículas 
em Educação Especial, chegando a 78,4\% na região sul. Em termos locais (nas redes investigadas), essa deficiência também se sobressai em relação às demais (ALMEIDA, 2016; PLETSCH, 2016).

Mesmo considerando que nem sempre os números possam condizer com a realidade, uma vez que pesquisadores nos alertam para possíveis equívocos em função de condições sociais e comportamentais e, até mesmo pelo sucateamento dos serviços públicos para o acompanhamento desses sujeitos (PLETSCH, 2014), os dados quantitativos chamam a atenção para a emergência em propiciar uma escolaridade que de fato beneficie os processos de escolarização, pois “entendemos que para além do acesso e permanência é preciso garantir ao sujeito com deficiência a garantia real de sua aprendizagem e seu consequente desenvolvimento" (PLETSCH; OLIVEIRA, 2015, p. 127).

O conceito de deficiência múltipla ou múltiplas deficiências diz respeito à associação numa mesma pessoa de duas ou mais deficiências primárias podendo ser de natureza física, sensorial ou intelectual (BRASIL, 1994; CARVALHO, 2000; ROCHA, 2014; ROCHA; PLETSCH, 2015). Sobre os primeiros resultados de nossas pesquisas, destacamos que os educandos com deficiência múltipla apresentavam, em sua maioria, a associação de deficiências envolvendo a deficiência intelectual. Apesar de não haver pleno consenso sobre o conceito da deficiência múltipla na literatura especializada, adotamos essa definição acompanhando o posicionamento oficial brasileiro que, apesar de não a explicitar na atual Política de Educação Especial (BRASIL, 2008), a considera de acordo com essa perspectiva em documentos anteriores (BRASIL, 1994) e, é assim tratada em outros documentos federais (BRASIL, 2000; 2002; 2004; GODOI, 2006).

Em relação à Política de 2008 não mencionar diretamente a deficiência múltipla, Araóz (2010) e Rocha (2014) levantam críticas, destacando que essa omissão leva a um distanciamento das políticas públicas de inclusão em relação à realidade vivenciada por essas pessoas, não atendendo assim as especificidades desses sujeitos. A este respeito, Rocha (2014) aponta aspectos os quais denomina como inadequações na implementação do AEE em relação ao processo de escolarização dos alunos com múltiplas deficiências. Inadequações que atrapalham a frequência desses alunos na sala de recursos multifuncionais ou até mesmo resultam em concepções equivocadas como a de que este 
serviço poderia ser substitutivo ao trabalho pedagógico realizado nas classes de ensino comum.

No que diz respeito ao AEE, indicadores nacionais apontam o avanço do Programa Implantação de Salas de Recursos Multifuncionais. Nas estatísticas, o Estado do Rio de Janeiro, no qual se situam os municípios foco das nossas pesquisas, encontra-se na faixa percentual em que até $49 \%$ das escolas públicas com matrículas de estudantes públicoalvo da Educação Especial estão contempladas com essas salas. Em relação à taxa de inclusão dos estudantes com deficiência na Educação Básica, o Estado apresenta o percentual de $75 \%$, estando um pouco abaixo do nível nacional que é de $79 \%$ (BRASIL, 2015).

Os dados das pesquisas realizadas no âmbito dos projetos aqui focados demonstram que ao longo dos anos, desde a proposição da Política de Educação Especial na Perspectiva da Educação Inclusiva, houve considerável aumento das matrículas do público da Educação Especial em turmas de ensino comum dos municípios participantes da investigação (ALMEIDA, 2016). Esse aumento acompanha, portanto, os índices nacionais (BRASIL, 2015). Em outros termos, isto evidencia que atualmente cada vez mais alunos têm tido a oportunidade de desenvolver sua escolaridade com seus pares, obtendo maior acesso ao ambiente escolar o que denota uma conquista histórica quando, até há pouco tempo, esses sujeitos eram obrigados a estar em ambientes segregados ou simplesmente não tinham acesso a nenhuma forma de aporte educacional (JANNUZZI, 2004; MAZZOTTA, 2005).

Em 2014, o quantitativo de matrículas de alunos da Educação Especial foi de 754.004, entre 4 e 17 anos de idade, matriculados na Educação Básica. Desse total, 611.917 foram de alunos com deficiência intelectual, sendo 448.503 matrículas em classe comum. Aliás, cabe dizer que desde 2004, o número de matrículas no ensino comum da população alvo da Educação Especial ascende ininterruptamente. Esse aumento implicou diretamente na queda das matrículas nas classes e escolas especiais que no levantamento de 2014 acusou 163.414 estudantes matriculados (BRASIL, 2015). No caso de alunos com múltiplas deficiências, em 2014 foi registrado um total de 67.903 matrículas, sendo a maior parte no ensino comum - 38.422 - número que teoricamente também se aproximaria das matrículas no AEE. Ainda assim, o quantitativo de estudantes com 
múltiplas deficiências em classes especiais é bastante expressivo - 29.481 (BRASIL, 2015). Em termos locais (nas redes pesquisadas) o quantitativo de alunos com deficiência intelectual e múltipla matriculados nas redes de ensino se dá de acordo com o quadro a seguir.

Quadro 1- Matrículas de alunos com deficiência intelectual e múltipla

\begin{tabular}{|l|c|c|c|}
\hline & $\begin{array}{c}\text { Total de alunos público alvo da } \\
\text { Educação Especial }\end{array}$ & $\begin{array}{c}\text { Alunos com } \\
\text { deficiência } \\
\text { intelectual }\end{array}$ & $\begin{array}{c}\text { Alunos com } \\
\text { múltiplas } \\
\text { deficiências }\end{array}$ \\
\hline Duque de Caxias & 2.315 & 1283 & 255 \\
\hline Belford Roxo & 918 & 292 & 295 \\
\hline São João de Meriti & 787 & 238 & 79 \\
\hline Mesquita & 407 & 308 & 14 \\
\hline Queimados & 407 & 308 & 14 \\
\hline Nova Iguaçu & 1.010 & 431 & 103 \\
\hline Nilópolis & 315 & 218 & 22 \\
\hline
\end{tabular}

Fonte: Banco de dados do grupo de pesquisa Observatório da Educação Especial e inclusão escolar: práticas curriculares e processos de ensino e aprendizagem (2013-2015)4.

É importante sinalizar que a maioria desses sujeitos continua matriculada em classes e/ou até mesmo escolas especiais, exceto na Rede Municipal de Queimados, onde, na atualidade, todos os alunos estão matriculados em classes comuns. No Município de Duque de Caxias, das 1.283 matrículas de alunos com deficiência intelectual, 363 frequentam as 41 classes especiais destinadas a essa população. No caso da deficiência múltipla, das 255 matrículas, apenas 94 estão em classes comuns e 161 continuam em 21 classes especiais. No Município de Belford Roxo chama atenção o número de matrículas de alunos com múltipla deficiência, que totaliza 295 sujeitos, em sua maioria (226 alunos), matriculados em uma escola especial. No caso das matrículas de estudantes com deficiência intelectual, verificamos que a maioria (178 alunos) também frequenta a mesma escola especial. Em Nilópolis, das 218 matrículas de alunos com deficiência intelectual, 121 estão em classes especiais. No caso da deficiência múltipla, das 22 matrículas, 7 em classe especial e as demais em turmas comuns de ensino. Sobre as redes municipais de educação de São João de Meriti, Nova Iguaçu e Mesquita, não temos dados específicos sobre as matrículas, mas, segundo as gestoras em entrevista, todas estão assumindo práticas e políticas para garantir a matrícula dos alunos no sistema comum de ensino.

\footnotetext{
${ }^{4}$ Os dados foram fornecidos pelas redes de ensino.
} 
Estes dados sinalizam para duas questões. Primeira, na Baixada Fluminense (municípios investigados) a escolarização dos alunos com deficiência intelectual e múltipla ocorre prioritariamente em espaços segregados, diferentemente do que mostram os indicadores federais. Segunda, conforme relato das gestoras, as classes especiais seriam ambientes provisórios que objetivam "preparar" os alunos para o ensino comum. Tal prática, a rigor, mantém a perspectiva da integração ${ }^{5}$ em detrimento dos princípios inclusionistas.

$\mathrm{Na}$ análise sobre os diferentes suportes para a escolarização dos alunos com deficiências nos municípios participantes da pesquisa, cada rede vem se organizando a partir de diferentes estratégias que abarcam as necessidades de suas realidades e condições estruturais e de recursos humanos. Almeida (2016), a partir do banco de dados do grupo de pesquisa especifica esses suportes, dentre os quais podemos exemplificar, em linhas gerais, desde a atuação de professores itinerantes ${ }^{6}$ e dos serviços relacionados ao AEE como em salas de recursos multifuncionais, classes hospitalares, atendimento domiciliar, como também núcleos ou polos para a realização de atendimentos especializados para além do trabalho pedagógico em articulação com outras áreas (fonoaudiologia, psicologia, fisioterapia, psicomotricidade, entre outros). Ações que em determinados municípios estavam mais organizadas e, em outros, com desafios consideráveis para atender as demandas do público da Educação Especial como um todo. Os dados demonstram o esforço dessas redes em atender à legislação federal (BRASIL, 2008; 2009).

Outro aspecto evidenciado em nossas pesquisas aponta para entraves relacionados à infraestrutura e à logística para a prática pedagógica (acesso a recursos de tecnologia assistiva, por exemplo) e até mesmo o acesso à escola por falta de acessibilidade física e de transporte acessível. Estes se revelam ainda mais no caso de alunos com múltiplas deficiências, que muitas das vezes dependem do transporte escolar

\footnotetext{
${ }^{5}$ Desenvolveu-se como uma proposta educacional que se propunha a oferecer aos alunos com deficiências o ambiente escolar menos restritivo possível, ou seja, que nele pudesse estar e participar à medida que fossem preparados para isso. Segundo Glat; Blanco: “(...) este modelo visava preparar alunos das classes e escolas especiais para ingressarem em classes regulares, quando receberiam, na medida das suas necessidades, atendimento paralelo em salas de recursos ou outras modalidades especializadas" (2009, p.22).

${ }^{6} \mathrm{O}$ ensino itinerante é realizado por um professor especializado em forma de apoio aos alunos com deficiências matriculados em turmas comuns e seus respectivos professores.
} 
adaptado e de adequações mais acentuadas nos espaços escolares. Juntamente com esses educandos, alunos com deficiência intelectual dependem de ações pedagógicas que partam de professores qualificados devendo ser fundamentadas em flexibilizações curriculares e, sobretudo em um trabalho colaborativo entre professor do ensino comum e do AEE. Desta forma, o processo de escolarização não ficaria restrito apenas à efetivação de matrículas, mas propiciaria condições de aprendizado e desenvolvimento. Infelizmente isso não se restringe apenas aos municípios da Baixada Fluminense, uma vez que outras pesquisas têm apontado essas dificuldades em outras regiões do país (LAPLANE, 2015; NERES; KASSAR, 2016; NUNES, 2016; SILVA, 2016; SOUZA, 2016; MENDES, 2016; SILVA, 2016).

Em termos legais, as redes participantes do projeto de pesquisa seguem as diretrizes do Plano Nacional de Educação. Em recente artigo, Pletsch (2016) discute como os municípios da Baixada Fluminense/RJ incorporaram as indicações da Meta 4 do Plano Nacional de Educação (BRASIL, 2014) nos seus respectivos Planos Municipais de Educação. Na leitura desses planos, é possível perceber as perspectivas e, principalmente, as contradições e desafios enfrentados na escolarização dos alunos público-alvo da Educação Especial. Especificamente isso se nota no caso dos estudantes com deficiência intelectual e, sobretudo, com deficiência múltipla.

Ressalta-se que o próprio texto da Meta 4 abre margem para que haja a manutenção de práticas não condizentes com a concepção de inclusão, uma vez que reproduz o termo preferencialmente ao dispor sobre o estabelecimento da educação das pessoas que são público da Educação Especial em escolas de ensino comum. Sobre isso Laplane (2015) chama atenção:

Sucessivas versões da Meta 4 acrescentaram 0 termo "preferencialmente" e afirmaram a garantia de Atendimento Educacional Especializado (AEE), inclusive em classes, escolas ou serviços especializados. A versão final é um texto ambíguo, que revela a persistência de embates entre os defensores de uma política inclusiva exclusivamente em salas de aula regular e aqueles que, por diferentes razões, sentem-se contemplados pela atual formulação. (p. 8) 
Os municípios participantes das pesquisas seguiram em seus planos essa tendência do documento nacional. Talvez por terem se sentido "contemplados" pela brecha do documento federal, conforme o mencionado na citação. Em todos os planos municipais foi possível observar a preocupação em apresentar o AEE como suporte para o processo de inclusão escolar, seguindo as orientações das diretrizes federais e apontando as salas de recursos multifuncionais como serviço para a sua implementação (PLETSCH, 2016).

Ainda sobre o AEE cabe ressaltar que apesar de haver outras modalidades para a sua implementação (BRASIL, 2009), na análise realizada por Almeida (2016) fica evidente que todos os municípios realizam este atendimento quase que exclusivamente por meio da sala de recursos multifuncionais. Esta passou a ser ofertada nas escolas em 2008. Ainda assim há o alerta sobre o perigo desse tipo de atendimento ser realizado de modo substitutivo ao ensino comum - ainda mais em caso de alunos com comprometimentos severos, conforme é o caso de grande parte dos alunos com múltiplas deficiências o que é completamente irregular em nossa percepção, pois tira do sujeito o direito de acesso à escola.

Também constatamos que, em grande medida, apesar dos esforços políticos das gestoras de Educação Especial, as práticas desenvolvidas no AEE seguem práticas terapêutico/adaptativas, atividades lúdicas com uso de jogos em detrimento de práticas focalizadas em processos de escolarização planejados e desenvolvidos a partir da colaboração com o professor do ensino regular. Os dados também mostraram que,

[...] o laudo continua, em grande medida, sendo usado como referência para garantir não apenas os direitos educacionais desses sujeitos como a matrícula nas salas de recursos multinacionais que integram 0 atendimento educacional especializado (AEE), como também, é usado como base para as práticas pedagógicas. (PLETSCH; OLIVEIRA, 2015, p. 130)

Considerando que a Nota Técnica 4 (BRASIL, 2014a), disponibilizada pela Diretoria de Políticas de Educação Especial, traz um conjunto de orientações para que as redes de ensino adotem procedimentos para a avaliação e o encaminhamento de alunos ao AEE, levando em conta o laudo médico apenas como um documento complementar e não 
como algo obrigatório para o acesso a este serviço, esperamos que essa realidade seja superada. Igualmente, compreendemos que o laudo não é o problema, mas sim, a forma como ele tem sido usado no contexto escolar. Também entendemos que, em grande medida, o laudo, em especial para pessoas com deficiência intelectual, tem sido elaborado de forma equivocada pelo sistema de saúde. Tal aspecto acaba contribuindo para fortalecer o estigma histórico vivenciado por estas pessoas e não como um instrumento para explicar e contribuir com o planejamento dos suportes pedagógico ou não necessários para ampliar as possibilidades educacionais e de inserção social desses sujeitos.

Ainda em relação ao $\mathrm{AEE}$, quando se analisam os dados coletados na Baixada Fluminense, nota-se que os municípios intencionam se adequar à legislação federal (BRASIL, 2008). Almeida (2016) nos traz elementos a respeito:

\begin{abstract}
Assim, os indicadores apresentados corroboram para uma perspectiva educacional que converge tanto em âmbito nacional, quanto em local. As questões que emergem para a discussão mostram-se engatilhadas no que diz respeito aos dados oficiais, refletindo tensões específicas no campo da educação especial. Ainda que os dados revelem relativa inclusão, esta mesma inclusão traz novas agruras já identificadas no curso deste processo. (p. 111)
\end{abstract}

A partir destas considerações, focaremos a partir de agora dados de pesquisas específicas realizadas nas redes de ensino aqui analisadas envolvendo diferentes dimensões sobre a escolarização de alunos com deficiência intelectual e múltipla, mas, sobretudo, mostrando a organização e a oferta do AEE para estes sujeitos.

No caso da deficiência múltipla, finalizamos uma dissertação de mestrado desenvolvida por Rocha (2014). Um de seus objetivos foi justamente discutir como o suporte pedagógico oferecido no $\mathrm{AEE}$ e as propostas pedagógicas ali realizadas têm contribuído para o processo de ensino e aprendizagem e, consequentemente, para o desenvolvimento dos alunos com deficiência múltipla. Os resultados, entre outros aspectos, evidenciam que, apesar do trabalho positivo realizado pelas professoras no $\mathrm{AEE}$, há a necessidade de oferecer aos sujeitos mais comprometidos uma rede de apoio com diferentes profissionais (como terapeuta ocupacional, fisioterapeuta, entre outros), 
a qual, todos sabemos, o sistema público oferece precariamente ou não oferece. Cabe dizer que estudos envolvendo esta população são escassos. Nessa direção, as nossas investigações, em andamento, podem contribuir e avançar na produção do conhecimento sobre os processos de escolarização e suportes especializados necessários para o desenvolvimento destes sujeitos.

No que se refere à escolarização de alunos com deficiência intelectual pesquisas como as de Oliveira (2016) apontam que as práticas pedagógicas observadas em uma das redes de ensino da Baixada Fluminense estão centradas no ensino tradicional e não contemplam as especificidades do aluno, bem como impossibilitam a presença de mediações pedagógicas. A este respeito, a autora ressalta que o professor regente da turma comum não possui uma formação voltada para atender as demandas da escolarização de pessoas com deficiência, além disso, em suas falas, registradas por meio de entrevistas, o docente demonstra que apesar de gostar do aluno, não acredita na sua capacidade de acompanhar o desenvolvimento da turma.

Essas falas não são incomuns; pesquisas como as de Pletsch (2014), Pletsch; Oliveira (2015) e Campos (2016) afirmam que as concepções docentes continuam fortemente marcadas pela crença na impossibilidade de aprendizagem dos alunos com deficiência intelectual. Com isso, destacamos que a formação inicial e continuada para os futuros professores e professores envolvidos na educação de alunos com deficiência intelectual, assim como deficiência múltipla, se faz urgente. Prioridade também deve ser dada a novos cursos que atentem para a realidade das redes escolares, isto é, uma formação mais vinculada às demandas cotidianas dos professores em sala de aula, almejando relações de ensino e aprendizagem que propiciem de fato o desenvolvimento. Em outras palavras, entendemos que não basta fomentar políticas que defendam a inclusão e discorram sobre uma série de aspectos do acesso escolar sem consolidar mudanças estruturais e pedagógicas no movimento funcional das escolas.

Isso nos leva a refletir sobre as práticas curriculares e as estratégias de ensino destinadas aos sujeitos com deficiência intelectual e múltipla. No caso das práticas curriculares dirigidas para a escolarização de alunos com deficiência intelectual, nossos dados de pesquisa indicam, assim como os estudos realizados por Ferri; Hostins (2008), Cathcart (2011), Braun (2012), Redig (2012), Pletsch; Oliveira (2015), que uma das maiores 
barreiras vivenciadas nas escolas se refere à falta de acesso ao currículo. Já, em relação aos sujeitos com múltiplas deficiências, essa demanda se amplia, pois muitos deles necessitam de intervenções mais específicas e sistematizadas com uso de recursos da comunicação alternativa e da tecnologia assistiva, os quais nem sempre estão disponíveis nas escolas públicas das redes participantes.

Em relação ao diálogo entre o currículo e o planejamento pedagógico, os resultados das pesquisas de Avila (2015) e Campos (2016), desenvolvidas, respectivamente, em Duque de Caxias e Nova Iguaçu, evidenciam que o Planejamento Educacional Individualizado (PEI) é uma importante estratégia para favorecer o Atendimento Educacional Especializado ( $A E E)$, ao passo que contribui para a promoção de práticas curriculares menos rígidas e mais contextualizadas. Ou seja, torna-se uma prática mediadora do processo de inclusão escolar.

Essa perspectiva aponta a urgência em compreendermos as estratégias pedagógicas enquanto práticas dialógicas. Conforme salienta Tacca (2014):

Entendemos, assim, que a estratégia pedagógica necessária aos processos de ensino-aprendizagem tem seus alicerces nas relações com a utilização plena do diálogo no trabalho compartilhado. O diálogo é o cerne da relação na aprendizagem, em que as partes envolvidas fazem trocas e negociam os diferentes significados do objeto do conhecimento, o que dá relevância ao papel ativo e altamente reflexivo, emocional e criativo do aluno e do professor. O conhecimento, assim, distancia-se de uma perspectiva mecanicista ou cognitivista que enfatiza quase que, exclusivamente, o produto da aprendizagem, ficando entendido como uma dinâmica que se constrói na confluência dialética entre o individual e o social, tendo em vista o desenvolvimento integral dos sujeitos envolvidos na educação. (p. 50)

Desse ponto de vista, por meio de uma aprendizagem colaborativa, pode ocorrer também o desenvolvimento da elaboração conceitual. Para Ferri; Hostins (2008) “conduzir as atividades pedagógicas dessa forma significa incluí-las numa proposta mais ampla, em que estão inter-relacionadas as ideias de currículo, material, formação docente, aprendizagem e desenvolvimento dos alunos" (p. 243). Partilhamos dessa opinião. Essas interações dialógicas estabelecidas entre professor e aluno e/ou aluno e aluno durante as práticas pedagógicas aumentam as possibilidades de apreensão dos 
conteúdos curriculares por pessoas com deficiência - especialmente de conhecimentos que envolvem operações simbólicas. Para que isso ocorra, reforçamos a necessidade de se desenvolver um trabalho colaborativo na escola, sobretudo entre os professores da turma comum e do AEE.

Refletindo sobre o trabalho colaborativo na prática docente, faz-se necessário mencionar que, no decorrer das pesquisas, verificamos que as trocas entre as professoras especialistas e as da sala comum, de maneira geral, não ocorreram. Os motivos são muitos, mas, de acordo com Almeida (2016), a principal queixa dos docentes se dá em virtude do atendimento ser realizado no contraturno, o que dificulta as interlocuções entre os profissionais. A falta de articulação ou trabalho colaborativo entre o professor do $A E E$ e do ensino comum também foi destaque na pesquisa de Baptista et al (2015) ao analisar o AEE em duas cidades do Estado do Rio Grande do Sul.

Ainda sobre o envolvimento dos professores no trabalho colaborativo, as entrevistas realizadas na pesquisa de Campos (2016) em uma escola da rede de Nova Iguaçu alertam que, além da falta de tempo entre os professores para tratarem de assuntos relativos aos alunos, o trabalho é perpassado por sentimentos de medo, desmotivação, impotência, constrangimento e culpa por não saber lidar com o planejamento dos alunos com deficiência intelectual.

Dito isso, precisamos problematizar um pouco mais essa questão, lembrando que o nosso objetivo não é apontar culpados e, sim, apontar o lugar e o papel que o AEE tem ocupado nas escolas como suporte especializado para garantir a escolarização de alunos com deficiência intelectual e múltipla em classes comuns. Nessa direção, há outros aspectos a serem considerados. Um deles é a compreensão de que o aluno com deficiência intelectual ou múltipla é responsabilidade somente do professor do AEE e não da escola como um todo, conforme aponta uma das gestoras responsáveis pela Educação Especial das redes na fala a seguir:

Enquanto o AEE for olhado até pela escola que o aluno com deficiência é dele, só dele, a gente não tem resultado. Por mais que seja o melhor profissional, enquanto a escola não abraça aquele aluno, não compartilha com aquele professor, não aproveita aquele profissional que sabe trabalhar... Este é o grande mal: a escola deposita todo o sucesso do 
aluno na sala de recursos. E só. (Entrevista realizada com as gestoras dia 17/11/2015 - banco de dados do grupo de pesquisa)

Outro aspecto importante e observado nos dados das pesquisas é que, por estar sendo considerada por muitos professores como uma "panaceia" educacional, a sala de recursos multifuncionais das redes tem recebido não só alunos com deficiências, transtornos globais do desenvolvimento e altas habilidades/superdotação, mas também alunos com "dificuldades de aprendizagem". Essa ação aumenta o número de atendimentos, sobrecarregando o trabalho do professor especialista, inclusive o tempo para planejamento. No banco de dados do grupo de pesquisa, encontramos o seguinte relato sobre tal prática:

O atendimento do aluno com deficiência intelectual - Rafael (nome fictício) - ocorre duas vezes por semana, embora por vezes presenciássemos o encurtamento do mesmo. Como Rafael já está alfabetizado, a nosso ver, ele pouco participa de atividades que contribuam para o desenvolvimento de novas aprendizagens, uma vez que estas são "facilitadas" para dar conta das especificidades de outros alunos com "dificuldade de aprendizagem" que participam junto com Rafael do atendimento. (Registro em diário de campo - agosto de 2015banco de dados do grupo de pesquisa)

Ainda sobre este aspecto, em entrevista, as gestoras afirmam que em alguns municípios esse atendimento ocorre por meio de projetos ou de uma "triagem" realizada por especialistas da rede. Observem os registros coligidos a seguir:

A gente gosta sempre de falar que a gente não atende só o aluno com deficiência. Inclusive nós estamos revendo no nosso projeto para o ano que vem. Aí agente vai recortar este público, porque da mesma forma que no início lá, quando a gente começou este projeto, ele foi muito interessante para gente. Hoje a gente já começa a perceber que tá surgindo alguns gols contra, então vamos mudar este placar aí. (Entrevista com as gestoras, realizada em 17/11/2015 - banco de dados do grupo de pesquisa).

E aí nós temos as salas de AEE que não é só atendido o aluno com deficiência, mas alunos que apresentam uma dificuldade extrema que estão sendo atendidos também. Tem uma triagem. Primeiro fazemos uma pré-avaliação com a equipe que a gente chama de equipe de 
acompanhamento especializado, que é dentro da gerência de educação especial. Então nós temos fonoaudiólogo, psicólogos, psicopedagogo e fisioterapeuta. Então eles fazem essa avaliação, a escola encaminha o nome destas crianças e eles fazem um acompanhamento por esta equipe. Ela não precisa realmente estar na Sala de Recursos também e aí eles são atendidos também pela Sala de Recursos e fazem o acompanhamento com especialista da área ou fisioterapeuta ou fonoaudiólogo, ou psicólogo e aí por diante. Só que tem um período. (Entrevista com as gestoras, realizada em 17/11/2015 - banco de dados do grupo de pesquisa)

Nas entrevistas é possível verificar a diversidade de ações e práticas desenvolvidas pelas redes de ensino para efetivar as diretrizes legais. A organização e a oferta do sistema de suportes são variadas, mas, em geral, focalizam o Atendimento Educacional Especializado por meio das salas de recursos multifuncionais. Nesse contexto, podemos inferir que as políticas federais têm impactado as redes de ensino da Baixada Fluminense no que diz respeito à inclusão escolar, e, apesar das contradições, é possível evidenciar pequenos avanços na garantia dos direitos educacionais das pessoas com deficiência intelectual e múltipla.

Em síntese, a organização e a oferta do Atendimento Educacional Especializado ocorre de forma diversificada para esta população e as diretrizes locais para efetivá-lo então em processo de implementação. Todavia, para que de fato e de direito as pessoas com deficiência intelectual múltipla tenham garantido seu desenvolvimento, é necessário que o Estado amplie os investimentos em recursos materiais e humanos e, sobretudo, avance em propostas políticas que possibilitem intervenções pedagógicas precoces e qualificadas. Para tal, mais uma vez sinalizamos para a indispensável qualificação dos professores de forma que os mesmos tenham acesso a conhecimentos sobre a complexidade e as possibilidades do ser humano por meio da apropriação da cultura. Igualmente, assim como dito na epígrafe inicial, sinalizamos para a necessária articulação e colaboração entre as propostas desenvolvidas nos contextos escolares com as práticas realizadas no cotidiano das salas de recursos multifuncionais, de forma que cada espaço educacional tenha clareza do seu papel e atuação no processo de escolarização de alunos com deficiência intelectual e múltipla. 


\section{Referências}

AMERICAN ASSOCIATION ON INTELLECTUAL AND DEVELOPMENTAL DISABILITIES. Intellectual disability: definition, classification, and systems of supports. Washington, DC: AAIDD, 2010.

ALMEIDA, Tamara França de. Análise dos indicadores e políticas de inclusão escolar na Baixada Fluminense. 2016, 155f. Dissertação (Mestrado em Educação, Contextos Contemporâneos e Demandas Populares) - Universidade Federal Rural do Rio de Janeiro, Seropédica, 2016.

ARAÓZ, Suzana Maria Mana de. Inclusão de alunos com deficiência múltipla: análise de um programa de poio. 2010. Tese (Doutorado em Educação) - Universidade Federal de São Carlos, São Carlos, SP, 2010.

AVILA, Leila Lopes de. O planejamento educacional individualizado (PEI) para pessoas com deficiência intelectual: uma construção colaborativa. 2015. Dissertação ( Mestrado em Educação) - UFRRJ/PPGEDUC/IM, Nova Iguaçu, março, 2015.

BAPTISTA, Claudio Roberto; SILVA, Carla Maciel da; CORREIA, Gilvane Belem. O atendimento educacional especializado: uma análise de premissas organizadoras e de contextos de implementação. Revista Diálogos e Perspectivas em Educação Especial, v. 2, n. 1, p43-54, 2015.

BRASIL. Ministério da Educação e Cultura. Política Nacional de Educação Especial educação especial, um direito assegurado. Brasília: MEC / SEESP, 1994.

BRASIL. Ministério da Educação e Cultura, Secretaria de Educação

Especial. Programa de Capacitação de Recursos Humanos do Ensino Fundamental: Deficiência Múltipla. Brasília, DF: Ministério da Educação, Secretaria de Educação Especial. Brasília, 2000. (Série Atualidades Pedagógicas).

BRASIL. Ministério da Educação e Cultura. Estratégias e orientações pedagógicas para a educação de crianças com necessidades educacionais especiais: dificuldades acentuadas de aprendizagem. Deficiência múltipla. Brasília: MEC/SEESP, 2002.

BRASIL. Ministério da Educação. Secretaria de Educação Especial. Saberes e práticas da inclusão: dificuldades acentuadas de aprendizagem - deficiência múltipla. Brasília: MEC/SEESP, 2004.

BRASIL. Política Nacional de Educação Especial na perspectiva da Educação Inclusiva. Brasília, 2008.

BRASIL. Resolução $\mathbf{n}^{\circ}$ 4, de 2 de outubro de 2009. Institui Diretrizes Operacionais para o Atendimento Educacional Especializado na Educação Básica, modalidade Educação Especial. Brasília, 2009. 
BRASIL. Lei 13.005 de junho de 2014. Plano Nacional de Educação. Brasília, 2014.

BRASIL. Nota técnica $\mathbf{n}^{\circ}$ 4. Brasília, $2014 a$.

BRASIL. Instituto Nacional de Estudos e Pesquisas Educacionais Anísio Teixeira. Microdados do Censo Escolar 2014. Brasília: INEP, 2014. Disponível em: <http://portal.inep.gov.br/basica-levantamentos-acessar>. Acesso em: maio de 2016.

BRASIL. Principais indicadores da educação de pessoas com deficiência. Censo MEC/INEP 2015. Brasília, 2015. Disponível em:

http://portal.mec.gov.br/index.php?option=com_docman\&view=download\&alias=1765secadi-principais-indicadores-da-educacao-especial\&category_slug=junho-2015 pdf\&Itemid=30192 Acesso em: abril de 2016.

BRASIL. A consolidação da inclusão escolar no Brasil (2003 a 2016). Brasília, 2016.

BRAUN, Patrícia. Uma intervenção colaborativa sobre os processos de ensino e aprendizagem do aluno com deficiência intelectual. 2012, 324f. Tese (Doutorado em Educação) - Universidade do Estado do Rio de Janeiro, Faculdade de Educação, Rio de Janeiro, 2012.

CAMPOS, Erika Costa Vliese Zichtl. Diálogos entre o currículo e o planejamento educacional individualizado (PEI) na escolarização de alunos com deficiência intelectual. 2016, 173 p. Dissertação (Mestrado em Educação) Universidade Federal Rural do Rio de Janeiro. 2016, PPGEduc, Rio de Janeiro, 2016.

CARVALHO, Erenice Natália Soares de. Programas e capacitação de recursos humanos do Ensino Fundamental: deficiência múltipla. Brasília: SEESP/MEC, 2000. v. 1.

CATHCART, Karla Demonti Passos. Crianças com deficiência mental na escola inclusiva: estratégias para aprender. 2011, 141f. Dissertação (Mestrado em Educação) - Universidade do Vale do Itajaí, Itajaí, 2011.

FERRI, Cássia; HOSTINS, Regina Célia Linhares. Práticas de seleção e organização do conhecimento nas escolas regulares e especiais. Revista Educação e Realidade, v. 33, n,2 p.231-252, jul./dez. 2008.

GLAT, Rosana; BLANCO, Leila de Macedo Varela. Educação Especial no contexto de uma Educação Inclusiva. In: GLAT, R. (Org.). Educação inclusiva: cultura e cotidiano escolar. Rio de Janeiro: Editora Sete Letras, 2007. p. 15-35 (Coleção Questões atuais em Educação Especial, v. VI).

GODÓI, Ana Maria de. Educação infantil: saberes e práticas da inclusão: dificuldades acentuadas de aprendizagem: deficiência múltipla. [4. ed.] - Brasília: MEC, Secretaria de Educação Especial, 2006. 
JANNUZZI, Gilberta de Martino. A educação do deficiente no Brasil: dos primórdios ao início do séc. XXI. Campinas, SP: Autores Associados, 2004.

LAPLANE, Adriana Lia Friszman de. O que os dados do censo escolar revelam sobre as barreiras à inclusão? Revista Educação e Fronteiras Online. Dourados, v. 5, n.13, maio/ago., 2015. Disponível em:

<http://ojs.ws.ufgd.edu.br/index.php?journal=educacao\&page=article\&op=view\&path\%5B $\% 5 \mathrm{D}=3762>$.

MAZZOTTA, Marcos José da Silveira. Educação especial no Brasil: história e políticas

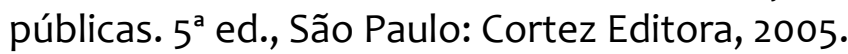

MENDES, Regina da Silva. A escolarização de alunos com deficiência intelectual no ensino fundamental da Rede de Ensino de Itajaí-SC. 2016, 128f. Dissertação (Mestrado em Educação) - Universidade do Vale do Itajaí, Itajaí/SC, 2016.

OLIVEIRA, Mariana Corrêa Pitanga de. A escolarização de alunos com deficiência intelectual à luz da perspectiva histórico-cultural: avaliação mediada e apropriação conceitual. 2016, 133 p. Dissertação (Mestrado em Educação) - Universidade Federal Rural do Rio de Janeiro, PPGEduc, Rio de Janeiro, 2016.

PLETSCH, Márcia Denise. A escolarização de pessoas com deficiência intelectual no Brasil: da institucionalização às políticas de inclusão (1973-2013). Revista Arquivos Analíticos de Políticas Educativas, v. 22, n. 81). Dossiê Educação Especial: diferenças, currículo e processos de ensino e aprendizagem. Editoras convidadas: Márcia Denise Pletsch \& Geovana Mendonça Lunardi Mendes. Disponível em: http://epaa.asu.edu/epaa/v22n81. Acessado em agosto de 2014.

PLETSCH, Márcia Denise; OLIVEIRA, Mariana Corrêa Pitanga de. Politicas de educação inclusiva: considerações sobre a avaliação da aprendizagem de alunos com deficiência intelectual. Revista Educação, Artes e Inclusão, v. 10, n. 2, p. 125-137, 2015.

PLETSCH, Márcia Denise. Educação especial e inclusão escolar nos Planos Municipais de Educação da Baixada Fluminense: avanços, contradições e perspectivas. Piracicaba/SP, 2016. Artigo aprovado para Revista Comunicações da UNIMEP. (Texto no prelo)

NERES, Celi Corrêa; KASSAR, Mônica de Carvalho Magalhães. Inclusão escolar de crianças com deficiência: do direito à matrícula ao acesso ao conhecimento em trajetórias escolares. Internacional Studies on Law and Education, v.22, p.39-50, jan./abr., 2016. NUNES, Isabel Matos. Política de educação especial para alunos com diagnóstico de deficiência múltipla: contornos e tensões. 2016, 240f. Tese (Doutorado em Educação), Universidade Federal do Espírito Santo, Vitória, 2016.

REDIG, Annie Gomes. Ressignificando a educação especial no contexto da educação inclusiva: a visão de professores especialistas. 2012, 184f. Dissertação (Mestrado em Educação) - Universidade do Estado do Rio de Janeiro. Rio de Janeiro, 2012. 
ROCHA, Maíra Gomes de Souza da. Processos de ensino e aprendizagem de alunos com múltiplas deficiências no AEE à luz da teoria histórico-cultural. 2014. 233 p. Dissertação (Mestrado em Educação) - Instituto de Educação - Universidade Federal Rural do Rio de Janeiro, Instituto Multidisciplinar, PPGEduc, Nova Iguaçu, RJ. 2014.

ROCHA, Maíra Gomes de Souza da; PLETSCH, Márcia Denise. Deficiência múltipla: disputas conceituais e políticas educacionais no Brasil. Revista Cadernos de Pesquisa. São Luís, Maranhão, v. 22, n. 1, , jan./abr. 2015.

\section{SILVA, Cristiane da. Elaboração conceitual no processo de escolarização de alunos com} deficiência intelectual no município de Balneário Camboriú: estratégias e mediações na elaboração de conceitos. 2016, 134f. Dissertação (Mestrado em Educação) - Universidade do Vale do Itajaí, Itajaí, 2016.

SOUZA, Flávia Faissal de. Atendimento educacional especializado: das diretrizes políticas à escolarização dos alunos com deficiência intelectual no ensino fundamental. 2016. Relatório apresentado ao Programa Nacional de Pós-Doutorado (CAPES), Programa de Pós-Graduação em Educação, Contextos Contemporâneos e Demandas Populares da UFRRJ.

TACCA, Maria Carmem Villela Rosa. Estratégias pedagógicas: conceituação e desdobramentos com o foco nas relações professor-aluno. In: TACCA, M. C. V. R. (Org.). Aprendizagem e trabalho pedagógico. 3. ed. Campinas, São Paulo: Alínea, 2014. p. 45-68.

Recebido em: 03/04/2016 Aprovado em: 07/05/2016

Universidade do Estado de Santa Catarina - UDESC Programa de Pós-Graduação em Educação - PPGE Revista Linhas Volume 17 - Número 35 - Ano 2016 revistalinhas@gmail.com 